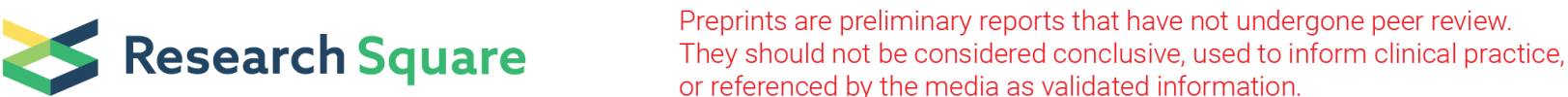

\section{Severity Distribution and Treatment of Chronic Obstructive Pulmonary Disease in China: Baseline Results of an Observational Study}

\section{Ting Yang}

China-Japan Friendship Hospital

\section{Baiqiang Cai}

Peking Union Medical College Hospital

\section{Bin Cao}

China-Japan Friendship Hospital

\section{Jian Kang}

The First Hospital of China Medical University: The First Affiliated Hospital of China Medical University

\section{Fuqiang Wen}

Sichuan University West China Hospital

\section{Yahong Chen}

Peking University Third Hospital

\section{Wenhua Jian}

First Affiliated Hospital Of Guangzhou Medical University

\section{Hongyan Shang}

AstraZeneca China

Chen Wang ( $\nabla$ wangchen66366@163.com )

China-Japan Friendship Hospital https://orcid.org/0000-0002-0529-2204

\section{Research}

Keywords: Chronic Obstructive Pulmonary Disease (COPD), Disease burden, COPD severity, Maintenance therapy, COPD management, Observational study, China, Outpatients

Posted Date: March 30th, 2021

DOI: https://doi.org/10.21203/rs.3.rs-346762/v1

License: (c) (1) This work is licensed under a Creative Commons Attribution 4.0 International License.

Read Full License 


\section{Abstract}

\section{Background}

Chronic obstructive pulmonary disease (COPD) receives low awareness and is undertreated in China. Understanding the burden and treatment of COPD across the nation is important for improving quality of care for this disease. This study aims to reveal the current situation of COPD severity distribution and management across China.

\section{Methods}

Baseline data from REALizing and Improving Management of Stable COPD in China, a multicentre, prospective, longitudinal, observational study, were analysed. Patients diagnosed with COPD as per Global Initiative for Chronic Obstructive Lung Disease 2016 (GOLD 2016) were enrolled from 50 randomly selected hospitals (tertiary, 25; secondary, 25) across six geographical regions. Data were collected in routine clinical settings.

\section{Results}

Between 15 December 2017 and 6 August 2020, 5013 patients were enrolled and 4978 included in the full analysis set. Of these, $2459(49.4 \%)$ reported ${ }^{3} 1$ exacerbation within 12 months, with a mean annual rate of 0.9 /patient, including 0.2 /patient and 0.5 /patient leading to emergency room visits and hospitalisation, respectively. Spirometry graded 458 (10.1\%), $1886(41.7 \%), 1558(34.5 \%)$, and 616 (13.6\%) were GOLD stage I-IV, and 536 (11.4\%), 1034 (22.0\%), 563 (12.0\%), and 2566 (54.6\%) were classified as GOLD 2016 Group A-D, respectively, without evident regional variations. Inhaled corticosteroids plus long-acting beta ${ }_{2}$-agonist (ICS/LABA, 1316 [26.4\%]), ICS/LABA plus long-acting muscarinic antagonist (ICS/LABA + LAMA, 871 [17.5\%]), and LAMA (754 [15.1\%]) were prescribed at high rates across all groups and regions. Medications not recommended by GOLD were commonly prescribed (TCM, 578 [11.6\%]; others, 951 [19.1\%]), and 681 (13.7\%) were not given ICS or long-acting bronchodilators.

\section{Conclusions}

Disease burden among Chinese COPD outpatients is high. Improved guideline adherence for COPD treatment is needed.

\section{Trial Registration}

ClinicalTrials.gov identifier, NCT03131362.

\section{Background}


Chronic obstructive pulmonary disease (COPD) is a progressive respiratory disease that represents a disproportionally high health burden in China compared with around the world. In China, it has a higher prevalence (8.2-13.7\% based on population surveys in China (1-3) vs a global age-standardized prevalence of $3.2 \%$ [male] $/ 2.0 \%$ [female] based on systematic reviews (4)) and higher mortality rate (agestandardized death rate for COPD, 79.4 per 100,000 in China vs 50.7 per 100,000 globally in 2013 (5)). In 2016, the estimated global prevalence of COPD was 251 million cases; with a population of 1.379 billion in China, the estimated prevalence would suggest between 113 and 187 million of the global cases being in China $(1-3,6,7)$. A number of 910,809 deaths due to COPD occurred in China in 2013, which accounted for about one-third of COPD-related deaths in the world (5). Even worse, it is projected to affect more people in the next decade due to the ageing population and increasing exposure to risk factors (8).

COPD is manifested by a wide spectrum of symptoms, varying by individual and changing over time (9). Whilst stable symptoms persist, acute episodes of exacerbations occur intermittently, reducing patient's quality of life and even leading to morbidity and mortality. The Global Initiative for Chronic Obstructive Lung Disease (GOLD) spirometric grading system classifies airflow limitation into four stages. For a thorough assessment of disease severity and risk of exacerbations, the combined COPD assessment system endorsed by GOLD 2016 is a more comprehensive tool (9). It integrates symptoms, airflow obstruction, and risk of exacerbations and offers a credible framework for stratifying patient and guiding treatment decisions. The Chinese Thoracic Society are responsible for national guidelines for COPD management and recommend the GOLD diagnosis and management guidelines (10).

Nationwide surveys revealed a diagnosis rate as low as $1 \%$ among Chinese patients with COPD (1). Of those diagnosed, approximately $11.7 \%$ received medications, including medications not intended for COPD treatment (1). Nonadherence to GOLD guidelines has been noted by previous studies, including the indiscriminate use of inhaled corticosteroids (ICS) (11), frequent use of short-acting bronchodilators (12), and prescription of medications beyond the recommended list $(13,14)$.

China has a three-tier healthcare system, where specialist care is provided by secondary and tertiary hospitals but qualified personnel and advanced facilities are concentrated in the tertiary hospitals. Poor guideline awareness, variations in institutional clinical practice, and high cost of some recommended medications in some areas such as those in the rural regions may hamper widespread adherence to the GOLD guidelines in China. The regional disparity in healthcare quality and lack of proper diagnosis and treatment of COPD may be associated with the high mortality rate of COPD in China (5). The first step to changing the status quo is a comprehensive knowledge of real-world clinical practice for managing COPD around China, which would provide a basis for policy making and resource allocation.

Here we present the baseline results from a multicentre, prospective, observational study on a nationally representative sample of Chinese COPD outpatients, providing insights into the characteristics, severity distribution, and treatment situation of COPD in China.

\section{Methods}




\section{Study design and patients}

This reflects the methodology to obtain the baseline data from the REALizing and Improving Management of Stable COPD in China (REAL; ClinicalTrials.gov: NCT03131362). This is a multicentre, prospective, observational study that aims to understand the distribution, clinical course and management of COPD in China. Hospitals were selected from six geographical regions using a multistage, stratified, and cluster sampling approach. Subject enrolment, assessment, and data collection took place in routine clinical settings, without additional intervention to participants.

Subjects were consecutively screened and enrolled during routine clinical visits to outpatient departments. Key inclusion criteria were: outpatients; 1 ) aged $\geq 40$ years; 2 ) diagnosed with COPD as per GOLD 2016, based on a post-bronchodilator fixed ratio of forced expiratory volume in 1 second $\left(\mathrm{FEV}_{1}\right)$ / forced vital capacity (FVC) $<70 \% ; 3$ ) symptoms characteristic of COPD; and 4) a history of exposure to risk factors (9). In order to include patients with stable COPD at enrolment, those experiencing acute exacerbations within 4 weeks of enrolment were excluded. A target sample size of 5000 subjects was determined, based on the primary objective of this study.

Detailed information on the sampling method, eligibility criteria, and sample size calculation has been reported (15).

\section{Ethics approval and consent to participate}

Written informed consent was obtained from all participants. The Ethics Committee of the China-Japan Friendship Hospital, the leading site, approved the study protocol and informed consent form (ICF) prior to study initiation (approval number 2016-97). All patients participating in this study voluntarily signed the ICF and received a copy before study initiation. The study was approved by ethics committees at individual study centres and performed in full conformance with the Declaration of Helsinki and Good Clinical Practice.

\section{Outcomes}

The primary objective of this longitudinal study was to observe the 1-year clinical outcomes of COPD under routine clinical treatment. Objectives addressed in this baseline study were to: 1 ) gain a crosssectional, nationwide view of COPD severity distribution, by GOLD stages and GOLD groups (pre-planned analysis as per GOLD 2016 (9) and post hoc as per GOLD 2017 (16); 2) reveal the pharmacological maintenance therapies used for routine treatment of COPD in clinical practice, across China, focussing on the prescriptions drug class for the GOLD groups (primarily by GOLD 2016 groups and exploratorily by GOLD 2017 groups) and by geographical region; and 3) describe the main non-pharmacological management approaches for COPD.

\section{Data source and assessment}

Baseline data were collected during patient's first study-related outpatient visit, scheduled by investigators for routine clinical care. Nonclinical and clinical data were collected from medical records, physician 
evaluations, and recorded in a case report form (see published methodology (15)). COPD severity, including airflow limitation severity and combined COPD assessment, were evaluated by investigators according to GOLD 2016 (9). Symptomatic assessment was based on both the COPD Assessment Test (CAT) and the modified Medical Research Council (mMRC) scores (more symptoms were defined by either CAT $\geq 10$ or $m M R C \geq 2$ ). Post hoc analysis was performed on COPD assessments according to GOLD 2017 (16).

\section{Statistical analysis}

Analysis was performed on the full analysis set (FAS), including all participants fulfilling eligible criteria and successfully enrolled. Participants with missing data were excluded from analysis. Descriptive statistics were applied to the baseline data. No hypothesis testing was performed. Kappa coefficient was calculated to assess the agreement between CAT and mMRC as a symptom rater to classify GOLD groups. Statistical analysis was performed with Statistical Analysis System (SAS) statistical software, version 9.2 or later.

\section{Results}

\section{Patient characteristics}

Between 15 December 2017 and 6 August 2020, 5097 patients were screened at 50 hospitals (25 tertiary and 25 secondary hospitals) across six geographical regions of China. Of these, 5013 were enrolled and 4978 (2597 and 2381 from tertiary and secondary hospitals, respectively) included in the FAS. Baseline post-bronchodilator spirometry measurements were available for $4903(98.8 \%)$ patients.

Most patients were male (79.5\%), with a mean age of 66.2 years (SD 8.9; Table 1). Patients were almost equally sampled from urban and rural areas (55.0\% vs $45.0 \%)$. They had low levels of education, with 1800 (36.2\%) having completed primary and 1665 (33.5\%) completed secondary school. Most patients' family incomes fell within a low-to-middle range (<3021 USD/year, 1260 [25.3\%]; 3021-22 659 USD/year, $3376[67.8 \%]$ ). Patients with a smoking history constituted a large proportion (previous, 2556 [51.3\%]; current, $1142[22.9 \%])$. 
Table 1

Patient characteristics ${ }^{\star}$

\begin{tabular}{|c|c|}
\hline Baseline characteristics & $N=4978$ \\
\hline Male, n/N (\%) & $3959 / 4978(79.5)$ \\
\hline Age (years), mean (SD) & $66.2(8.9)$ \\
\hline $\mathrm{BMI}\left(\mathrm{kg} / \mathrm{m}^{2}\right)$, mean $(\mathrm{SD})$ & $23.0(3.6)$ \\
\hline \multicolumn{2}{|c|}{ Region of residence, $\mathrm{n} / \mathrm{N}(\%)$} \\
\hline North & $1005 / 4978(20.2)$ \\
\hline Northeast & $623 / 4978(12.5)$ \\
\hline East & $1248 / 4978(25.1)$ \\
\hline South central & $904 / 4978$ (18.2) \\
\hline Southwest & $596 / 4978(12.0)$ \\
\hline Northwest & $602 / 4978(12.1)$ \\
\hline \multicolumn{2}{|l|}{ Residence area, $\mathrm{n} / \mathrm{N}(\%)$} \\
\hline Urban & $2735 / 4972(55.0)$ \\
\hline Rural & $2237 / 4972(45.0)$ \\
\hline \multicolumn{2}{|l|}{ Highest education, n/N (\%) } \\
\hline Illiterate & $165 / 4976(3.3)$ \\
\hline Primary school & $1800 / 4976(36.2)$ \\
\hline Secondary school & $1665 / 4976(33.5)$ \\
\hline High/Technical school & 779/4976 (15.7) \\
\hline University/College & $556 / 4976(11.2)$ \\
\hline Graduate and above & $11 / 4976(0.2)$ \\
\hline \multicolumn{2}{|c|}{ Annual per-capita household income (USD), ${ }^{\dagger} \mathrm{n} / \mathrm{N}(\%)$} \\
\hline$<3021$ & $1260 / 4978(25.3)$ \\
\hline
\end{tabular}

* All percentages were calculated based on patients with available data; ${ }^{\dagger}$ Income was queried on a RMB basis and grouped into five intervals ( $<20000 \mathrm{RMB}, 20$ 000-150 $000 \mathrm{RMB}, 150000-300000$ $\mathrm{RMB}, 300$ 000-500 $000 \mathrm{RMB}$, and >500 $000 \mathrm{RMB}$ ), which were herein converted to USD using the 2018 yearly average exchange rate 6.62 and rounded up; ${ }^{\ddagger}$ pack-years data were missing for 16 patients; $\S$ reported respiratory disease history of patient's first-degree relatives.

SD, standard deviation; BMI, body mass index. 


\section{Baseline characteristics}

$3021-22659$

$22659-45317$

$45317-75528$

$>75528$

Occupation, $\mathrm{n} / \mathrm{N}(\%)$

White collar worker

Blue collar worker

Government officer

Unemployed

Retired

Smoking status, $\mathrm{n} / \mathrm{N}(\%)$

Non-smoker

Current smoker

Former smoker

Passive smoker

Pack-years, ${ }^{\ddagger}$ mean (SD)

Exposure to noxious particles or gases, $\mathrm{n} / \mathrm{N}$ (\%)

No exposure

Dust

Harmful gas

Biofuels

Other noxious substances

A family history of respiratory disease, $\S \mathrm{n} / \mathrm{N}(\%)$
$\mathrm{N}=4978$

$3376 / 4978$ (67.8)

278/4978 (5.6)

$35 / 4978(0.7)$

29/4978 (0.6)

$379 / 4978(7.6)$

$1685 / 4978$ (33.8)

$139 / 4978(2.8)$

$1233 / 4978(24.8)$

2047/4978 (41.1)

$1280 / 4978(25.7)$

$1142 / 4978(22.9)$

2556/4978 (51.3)

$1409 / 4975$ (28.3)

$42.1(24.1)$

$3397 / 4978$ (68.2)

$996 / 4978(20.0)$

$404 / 4978(8.1)$

$564 / 4978(11.3)$

$73 / 4978(1.5)$

$1715 / 4978(34.5)$

${ }^{*}$ All percentages were calculated based on patients with available data; ${ }^{\dagger}$ Income was queried on a RMB basis and grouped into five intervals ( $<20000 \mathrm{RMB}, 20000-150000 \mathrm{RMB}, 150000-300000$ $\mathrm{RMB}, 300$ 000-500 $000 \mathrm{RMB}$, and >500 000 RMB), which were herein converted to USD using the 2018 yearly average exchange rate 6.62 and rounded up; ${ }^{\ddagger}$ pack-years data were missing for 16 patients; $\S$ reported respiratory disease history of patient's first-degree relatives.

SD, standard deviation; BMI, body mass index. 
Almost half the patients experienced at least one exacerbation during the previous 12 months (2459 [49.4\%]; Table 2), at an average rate of 0.9 (SD 1.5) per patient per year. Exacerbations leading to emergency room visits and hospitalisation occurred at an average rate of 0.2 (SD 0.6 ) and 0.5 (SD 0.9) per patient per year, respectively. Blood eosinophil counts for 564 patients showed that $378(67.0 \%)$ had $\geq 100$ cells $/ \mu \mathrm{L}$ and $109(19.3 \%) \geq 300$ cells $/ \mu \mathrm{L}$. 
Table 2

Clinical characteristics of patients at baseline*

\section{Clinical characteristics}

Time since COPD diagnosis (years), ${ }^{\dagger}$ mean (SD)

Diagnosed as chronic bronchitis, n/N (\%)

Diagnosed as emphysema, n/N (\%)

COPD signs and symptoms, $\mathrm{n} / \mathrm{N}(\%)$

Shortness of breath

Wheezing

Chest tightness

Cough

Mucus purulence

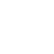

$$
(S D)
$$




\begin{tabular}{|c|c|}
\hline Clinical characteristics & $N=4978$ \\
\hline Annual exacerbations leading to hospitalisation per patient, mean (SD), range & $0.5(0.9), 0-10$ \\
\hline Concurrent respiratory diseases," n/N (\%) & $\begin{array}{l}1288 / 4978 \\
(25.9)\end{array}$ \\
\hline Asthma & 437/4978 (8.8) \\
\hline Respiratory infection & $422 / 4978(8.5)$ \\
\hline Bronchiectasis & $151 / 4978(3.0)$ \\
\hline Non-respiratory comorbidities," n/N (\%) & $\begin{array}{l}1981 / 4978 \\
(39.8)\end{array}$ \\
\hline Hypertension & $\begin{array}{l}1028 / 4978 \\
(20.7)\end{array}$ \\
\hline Coronary artery disease & $313 / 4978(6.3)$ \\
\hline Diabetes mellitus & $247 / 4978(5.0)$ \\
\hline Benign prostatic hyperplasia & $168 / 4978(3.4)$ \\
\hline Chronic gastritis & $111 / 4978(2.2)$ \\
\hline \multicolumn{2}{|c|}{$\begin{array}{l}{ }^{*} \text { All percentages were calculated based on patients with available data; }{ }^{\dagger} \text { Time since COPD diagnosis } \\
\text { was missing for } 26 \text { patients; }{ }^{\ddagger} \text { CAT and mMRC data were missing for two patients; } \$ \text { COPD-Q scores } \\
\text { were missing for five patients; }{ }^{\prime \prime} \text { diseases with a prevalence }>2 \% \text {. }\end{array}$} \\
\hline $\begin{array}{l}\text { CAT, COPD Assessment Test; COPD, chronic obstructive pulmonary disease; mi } \\
\text { Research Council; COPD-Q, COPD knowledge questionnaire; SD, standard devia }\end{array}$ & modified Medical \\
\hline
\end{tabular}

Patients on average scored 5.9 (out of 13) on the COPD knowledge questionnaire, which did not differ between urban and rural areas or between tertiary and secondary hospitals (Table 3), indicating patients' poor understanding of COPD. 
Table 3

Baseline characteristics, COPD severity, and prescribed maintenance medications by residential area and by hospital tier*

\begin{tabular}{|c|c|c|c|c|}
\hline & $\begin{array}{l}\text { Urban } \\
\text { area } \\
(\mathrm{N}=2735)\end{array}$ & $\begin{array}{l}\text { Rural } \\
\text { area } \\
(\mathrm{N}=2237)\end{array}$ & $\begin{array}{l}\text { Tertiary } \\
\text { hospitals } \\
(\mathrm{N}=2597)\end{array}$ & $\begin{array}{l}\text { Secondary } \\
\text { hospitals } \\
(\mathrm{N}=2381)\end{array}$ \\
\hline \multicolumn{5}{|c|}{ Severity of Airflow Limitation (GOLD stage), n/N (\%) } \\
\hline I & $\begin{array}{l}294 / 2524 \\
(11.6)\end{array}$ & $163 / 1988(8.2)$ & $\begin{array}{l}270 / 2337 \\
(11.6)\end{array}$ & 188/2181 (8.6) \\
\hline II & $\begin{array}{l}1127 / 2524 \\
(44.7)\end{array}$ & $\begin{array}{l}756 / 1988 \\
(38.0)\end{array}$ & $\begin{array}{l}1028 / 2337 \\
(44.0)\end{array}$ & $\begin{array}{l}858 / 2181 \\
(39.3)\end{array}$ \\
\hline III & $\begin{array}{l}805 / 2524 \\
(31.9)\end{array}$ & $\begin{array}{l}751 / 1988 \\
(37.8)\end{array}$ & $\begin{array}{l}753 / 2337 \\
(32.2)\end{array}$ & $\begin{array}{l}805 / 2181 \\
(36.9)\end{array}$ \\
\hline IV & $\begin{array}{l}298 / 2524 \\
(11.8)\end{array}$ & $\begin{array}{l}318 / 1988 \\
(16.0)\end{array}$ & $\begin{array}{l}286 / 2337 \\
(12.2)\end{array}$ & $\begin{array}{l}330 / 2181 \\
(15.1)\end{array}$ \\
\hline \multicolumn{5}{|c|}{ GOLD 2016, n/N (\%) } \\
\hline A & $\begin{array}{l}397 / 2585 \\
(15.4)\end{array}$ & $138 / 2108(6.5)$ & $\begin{array}{l}395 / 2413 \\
(16.4)\end{array}$ & $141 / 2286(6.2)$ \\
\hline B & $\begin{array}{l}602 / 2585 \\
(23.3)\end{array}$ & $\begin{array}{l}431 / 2108 \\
(20.4)\end{array}$ & $\begin{array}{l}603 / 2413 \\
(25.0)\end{array}$ & $\begin{array}{l}431 / 2286 \\
(18.9)\end{array}$ \\
\hline C & $\begin{array}{l}338 / 2585 \\
(13.1)\end{array}$ & $\begin{array}{l}225 / 2108 \\
(10.7)\end{array}$ & $\begin{array}{l}299 / 2413 \\
(12.4)\end{array}$ & $\begin{array}{l}264 / 2286 \\
(11.5)\end{array}$ \\
\hline D & $\begin{array}{l}1248 / 2585 \\
(48.3)\end{array}$ & $\begin{array}{l}1314 / 2108 \\
(62.3)\end{array}$ & $\begin{array}{l}1116 / 2413 \\
(46.2)\end{array}$ & $\begin{array}{l}1450 / 2286 \\
(63.4)\end{array}$ \\
\hline \multicolumn{5}{|c|}{ GOLD 2017, n/N (\%) } \\
\hline A & $\begin{array}{l}574 / 2733 \\
(21.0)\end{array}$ & $\begin{array}{l}243 / 2237 \\
(10.9)\end{array}$ & $\begin{array}{l}602 / 2595 \\
(23.2)\end{array}$ & $216 / 2381(9.1)$ \\
\hline B & $\begin{array}{l}1129 / 2733 \\
(41.3)\end{array}$ & $\begin{array}{l}951 / 2237 \\
(42.5)\end{array}$ & $\begin{array}{l}1173 / 2595 \\
(45.2)\end{array}$ & $\begin{array}{l}910 / 2381 \\
(38.2)\end{array}$ \\
\hline C & $212 / 2733(7.8)$ & $151 / 2237(6.8)$ & $155 / 2595(6.0)$ & $208 / 2381(8.7)$ \\
\hline
\end{tabular}

\footnotetext{
* All percentages were calculated based on patients with available data; ${ }^{\dagger}$ COPD-Q scores were missing for three and two patients from urban and rural areas, and for two and three patients from tertiary and secondary hospitals, respectively.

COPD, chronic obstructive pulmonary disease; COPD-Q, COPD knowledge questionnaire; GOLD, Global Initiative for Chronic Obstructive Lung Disease; ICS, inhaled corticosteroid; LABA, long-acting beta ${ }_{2}$ agonist; LAMA, long-acting muscarinic antagonist; SABA, short-acting beta ${ }_{2}$-agonist; SAMA, shortacting muscarinic antagonist; TCM, traditional Chinese medicine.
} 


\begin{tabular}{|c|c|c|c|c|}
\hline & $\begin{array}{l}\text { Urban } \\
\text { area } \\
(\mathrm{N}=2735)\end{array}$ & $\begin{array}{l}\text { Rural } \\
\text { area } \\
(\mathrm{N}=2237)\end{array}$ & $\begin{array}{l}\text { Tertiary } \\
\text { hospitals } \\
(\mathrm{N}=2597)\end{array}$ & $\begin{array}{l}\text { Secondary } \\
\text { hospitals } \\
(\mathrm{N}=2381)\end{array}$ \\
\hline D & $\begin{array}{l}818 / 2733 \\
(29.9)\end{array}$ & $\begin{array}{l}892 / 2237 \\
(39.9)\end{array}$ & $\begin{array}{l}665 / 2595 \\
(25.6)\end{array}$ & $\begin{array}{l}1047 / 2381 \\
(44.0)\end{array}$ \\
\hline $\begin{array}{l}\text { COPD-Q score }{ }^{\dagger} \text { mean } \\
\text { (SD) }\end{array}$ & $5.9(2.1)$ & $6.0(2.0)$ & $5.8(2.1)$ & $6.1(1.9)$ \\
\hline \multicolumn{5}{|c|}{ Prescribed mono- or combination therapy maintenance therapies for COPD, $n / N(\%)$} \\
\hline ICS & $3 / 2735(0.1)$ & $2 / 2237(0.1)$ & $2 / 2597(0.1)$ & $3 / 2381(0.1)$ \\
\hline LABA & $22 / 2735(0.8)$ & $9 / 2237(0.4)$ & $9 / 2597(0.3)$ & 22/2381 (0.9) \\
\hline ICS/LABA & $\begin{array}{l}619 / 2735 \\
(22.6)\end{array}$ & $\begin{array}{l}696 / 2237 \\
(31.1)\end{array}$ & $\begin{array}{l}682 / 2597 \\
(26.3)\end{array}$ & $\begin{array}{l}634 / 2381 \\
(26.6)\end{array}$ \\
\hline SABA & $34 / 2735(1.2)$ & $68 / 2237(3.0)$ & $11 / 2597(0.4)$ & $91 / 2381(3.8)$ \\
\hline SAMA & $13 / 2735(0.5)$ & $14 / 2237(0.6)$ & $6 / 2597(0.2)$ & $21 / 2381(0.9)$ \\
\hline SABA/SAMA & $1 / 2735(0.0)$ & $1 / 2237(0.0)$ & 2/2597 (0.1) & 0 \\
\hline LAMA & $\begin{array}{l}500 / 2735 \\
(18.3)\end{array}$ & $\begin{array}{l}252 / 2237 \\
(11.3)\end{array}$ & $\begin{array}{l}479 / 2597 \\
(18.4)\end{array}$ & $\begin{array}{l}275 / 2381 \\
(11.5)\end{array}$ \\
\hline ICS/LABA + LAMA & $\begin{array}{l}533 / 2735 \\
(19.5)\end{array}$ & $\begin{array}{l}336 / 2237 \\
(15.0)\end{array}$ & $\begin{array}{l}604 / 2597 \\
(23.3)\end{array}$ & $\begin{array}{l}267 / 2381 \\
(11.2)\end{array}$ \\
\hline Methylxanthines & $71 / 2735$ (2.6) & 133/2237 (5.9) & 33/2597 (1.3) & 171/2381 (7.2) \\
\hline TCM & $38 / 2735$ (1.4) & 42/2237 (1.9) & 23/2597 (0.9) & $57 / 2381(2.4)$ \\
\hline \multicolumn{5}{|c|}{$\begin{array}{l}\text { * All percentages were calculated based on patients with available data; }{ }^{\dagger} \text { COPD-Q scores were } \\
\text { missing for three and two patients from urban and rural areas, and for two and three patients from } \\
\text { tertiary and secondary hospitals, respectively. }\end{array}$} \\
\hline \multicolumn{5}{|c|}{$\begin{array}{l}\text { COPD, chronic obstructive pulmonary disease; COPD-Q, COPD knowledge questionnaire; GOLD, Global } \\
\text { Initiative for Chronic Obstructive Lung Disease; ICS, inhaled corticosteroid; LABA, long-acting beta } 2^{-} \\
\text {agonist; LAMA, long-acting muscarinic antagonist; SABA, short-acting beta }{ }_{2} \text {-agonist; SAMA, short- } \\
\text { acting muscarinic antagonist; TCM, traditional Chinese medicine. }\end{array}$} \\
\hline
\end{tabular}

\section{Severity distribution}

Based on spirometry measurements, 458 (10.1\%), 1886 (41.7\%), 1558 (34.5\%), and 616 (13.6\%) patients were classified as GOLD stage I, II, III, and IV, respectively (Fig. 1A). Evaluated as per GOLD 2016, 536 (11.4\%), 1034 (22.0\%), 563 (12.0\%), and 2566 (54.6\%) patients were classified as Group A, B, C and D 
(Fig. 1B). Re-evaluated as per GOLD 2017, for the post-hoc analysis, Group B (2083 [41.9\%]) constituted the largest group, followed by Group D (1712 [34.4\%], see Figure E1 in the Online Supplement).

A comparison between CAT and mMRC as a symptom rater to classify GOLD groups showed that the symptom severity cutoff CAT $\geq 10$ and breathless cutoff $m M R C \geq 2$ had moderate agreement in categorising both GOLD 2016 and GOLD 2017 groups (Kappa coefficient, 0.481 across GOLD 2016 groups, 0.505 across GOLD 2017 groups, Table 4).

Table 4

Distribution of patients across GOLD groups using either CAT or mMRC as a symptom rater

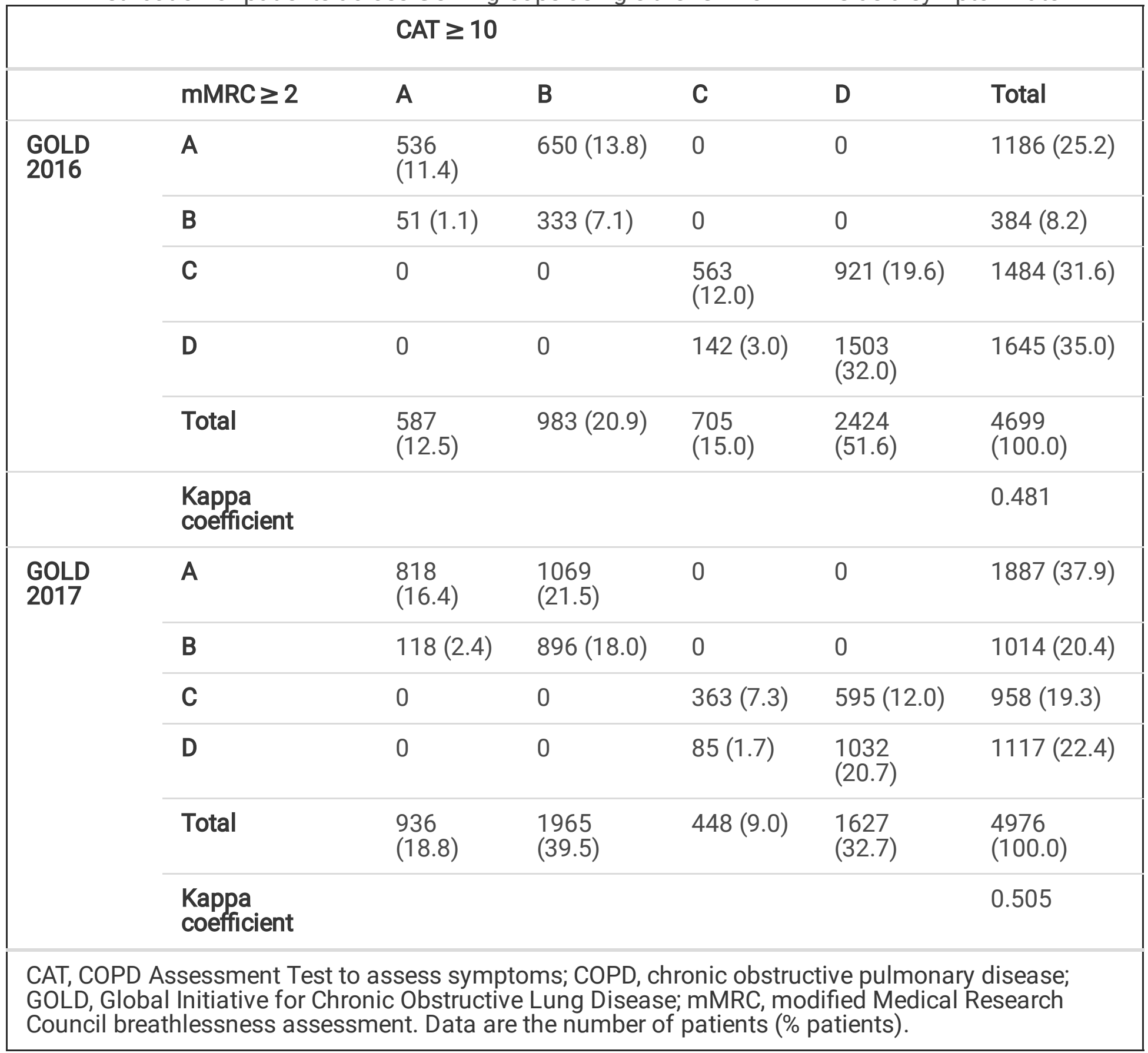


Severity distribution between urban and rural areas was generally similar, with notable exceptions being a higher proportion of patients in GOLD Group A and a lower proportion of patients in Group D in urban than in rural areas and in tertiary hospitals than in secondary hospitals (with both GOLD 2016 and GOLD 2017, Table 3).

More patients had a blood eosinophil count $\geq 300$ cells/ $\mu \mathrm{L}$ in Group A/C than in Group B/D (see Figure E2 in the Online Supplement).

\section{Pharmacological and non-pharmacological treatments}

Inhaled corticosteroids and long-acting beta ${ }_{2}$-agonist combinations (ICS/LABA, 1316 [26.4\%]), ICS/LABA plus long-acting muscarinic antagonists (ICS/LABA + LAMA, 871 [17.5\%]), and LAMA alone (754 [15.1\%]) were the most commonly prescribed maintenance therapies (Fig. 2A and see Table E1 in the Online Supplement). However, many patients (681 [13.7\%]) were not prescribed ICS or long-acting bronchodilators, the mainstay long-term inhaled medications, for symptom alleviation. Methylxanthines (705 [14.2\%]) and mucolytics (785 [15.8\%]) were also frequently prescribed (Fig. 2B and see Table E2 in the Online Supplement). Traditional Chinese medicine (TCM, 578 [11.6\%]) and other medications, such as leukotriene inhibitors/ methoxyphenamine (non-recommended medications, were commonly prescribed (951 [19.1\%]). Overall, ICS containing therapy was not prescribed based on blood eosinophil count: it was used by $67.7 \%$ of patients with a blood eosinophil count $<100$ cells $/ \mu \mathrm{L}, 62.1 \%$ of those with a blood eosinophil count $\geq 100$ cells $/ \mu \mathrm{L}$ and $<300$ cells $/ \mu \mathrm{L}$, and $67.9 \%$ of those with a blood eosinophil count $\geq$ 300 cells $/ \mu \mathrm{L}$.

An increasing percentage of ICS/LABA + LAMA use was noted from GOLD stage I to IV, and its use was more common in GOLD 2016 Group C and D (see Table E1 and Table E3 in the Online Supplement). ICS/LABA, ICS/LABA + LAMA, and LAMA alone constituted the main therapies in all GOLD 2016 groups (22.4-29.1\%, 13.4-19.9\%, and 10.7-26.7\%, respectively). Despite having more symptoms and/or higher risk of exacerbations, 156 (15.1\%) patients in Group B, 57 (10.1\%) in Group C, and 391 (15.2\%) in Group D were not prescribed ICS or long-acting bronchodilators (see Table E2 in the Online Supplement). Reanalysis according to GOLD 2017 revealed a consistent pattern and conclusion (see Table E4 and Table E5 in the Online Supplement).

The preferences for classes of maintenance therapies prescribed did not vary much by regional location (see Table E6 in the Online Supplement). Regionally, highest incidence of non-recommended medication prescription, excluding TCM, occurred in the south-central region (310 [34.3\%], see Table E7 in the Online Supplement).

Prescription of class of maintenance therapy was influenced by tier of hospital and rural/urban location (Table 3). LAMA monotherapy and ICS/LABA + LAMA were more commonly used whereas short-acting beta $_{2}$-agonists (SABA) and methylxanthines were less commonly used in urban areas than in rural areas and by tertiary hospitals than by secondary hospitals. In addition, rural areas also used ICS/LABA more often than urban areas. 
Non-pharmacological treatments for COPD included patient education (2976 [59.8\%]), smoking cessation (3342 [67.1\%]), breathing exercise (1567 [31.5\%]), and vaccination (391 [7.9\%], mainly for pneumonia [4.5\%] and influenza [4.9\%]).

\section{Discussion}

This study provided an overview of the severity and management of COPD based on a sample of outpatients in China. Most Chinese patients with COPD belonged to GOLD stage II/III and GOLD 2016 Group $D$, without notable variations across regions in COPD severity distribution. ICS/LABA, ICS/LABA + LAMA, and LAMA were commonly prescribed as maintenance therapies for all severity groups and in all regions, and non-recommended medications were also frequently used. Location urban/rural status and tier of hospital did influence the choice of therapy, with triple combination therapy more commonly used in tertiary setting and urban locations. Our results highlighted high disease burden and unstandardized COPD treatment in China.

The sociodemographic profile of COPD patients depicted by our cohort is consistent with that in previous studies, which epitomises characteristics of the Chinese COPD population at large: a higher prevalence among men and the elderly, a high prevalence of smoke exposure $(1,2)$, and low levels of education in patients with COPD $(2,11)$. These features are also recognised as risk factors for COPD (17). Though having been diagnosed with COPD for a mean of 3.8 years, patients enrolled in our study still had inadequate knowledge of this disease, suggesting a need for patient education.

The proportion of exacerbation in this study was $49.4 \%$, and higher than that reported by Fang, et al. $(5.9 \%)$ (1) but lower than that by Cui, et al. (62.7\%) (11). The differences might reflect the respective study populations, Fang et al. (1) examined all COPD patients above 40 years, while our study and Cui et al. (11) examined COPD outpatients above 40 years. Exacerbations requiring hospitalisation or emergency room visits occurred at a rate of 0.5 and 0.2 per patient per year, respectively, indicating a high disease burden among Chinese outpatients with COPD and inadequacy in disease stabilisation and exacerbation prevention.

Published data on the distribution of COPD stages in China are conflicting, likely due to different diagnostic criteria and sampling strategies. Several population-based studies that collected data by onsite interview and physical examination and diagnosed COPD based on spirometry only characterised Chinese patients with COPD as being mostly mild in severity $(2,18)$. The BOLD study estimated that about $85.1 \%$ of COPD patients in China belonged to GOLD stage I and II (18), while the China Pulmonary Health study reported an even higher proportion (GOLD stage I/II $>90 \%$ ) (2). Similarly, a nationwide survey found that GOLD stage I and II constituted $56.4 \%$ and $36.3 \%$, respectively (1). In contrast to previous reports $(1,2,18)$, we showed that stage II $(41.7 \%)$ and III $(34.5 \%)$ were most prevalent. One possible explanation for this discrepancy is that early-stage patients who are asymptomatic or have tolerable symptoms may not seek medical advice and remain undiagnosed, leading to underrepresentation in our study. The discrepancy in the proportion of patients with early-stage COPD 
also suggests that strategies to improve early diagnosis, via education and screening, for instance, are needed in China. However, our data $(54.6 \%)$ and other studies $(43.0-70.7 \%)(11,19)$ consistently showed predominance by Group D, who have more symptoms and high risk of exacerbations and mortality (20, 21). Although a regional divide in COPD prevalence exists in China $(20.2 \%$ in the southwest vs $10.2 \%$ in central China) (1), severity distribution did not appear to vary across geographical regions in our study. However, rural areas and secondary hospitals seem to have a higher disease burden based on a larger proportion of Group D patients.

A change in the combined assessment system was stipulated by GOLD 2017, in which airflow limitation no longer factors into the assessment (16) based on findings that it does not help improve prediction of exacerbation or mortality $(22,23)$. It remains unclear whether GOLD 2017 outperforms GOLD 2016 in stratifying patients and guiding treatment decisions. Both frameworks classify patients into clinically homogeneous groups $(20,21,24)$. Switching from GOLD 2016 to GOLD 2017 led to a redistribution of patients among different groups in our study, especially reducing the proportion of Group D whilst increasing that of Group B, consistent with previous reports $(11,19)$. Follow-up on these patients' disease progression and treatment outcomes will provide real-world evidence for comparing two systems.

Although the results on maintenance medications do not allow a precise estimate of adherence/nonadherence to GOLD guidelines due to no differentiation between initial and subsequent treatments, they revealed widely prescribed medications for COPD maintenance in China. Overall, longacting bronchodilators were more widely used than short-acting bronchodilators, which is in line with current guidelines (9). However, notable deviations from guidelines were observed $(9,16)$. Dual ICS/LABA and triple ICS/LABA + LAMA therapy seemed to be overused, especially for Group A and B, which was also shown by another study (11). Triple therapy was used at a slightly higher rate in GOLD stage III/IV and GOLD 2016 Group C/D but not in GOLD 2017 Group C/D, indicating that the prescription was based on severe/very severe airflow limitation, probably with an aim to relieve symptoms in these patients. In addition, the current lack of access to dual bronchodilators in China might result in the low rate of LABA + LAMA prescription. Alarmingly, a great number of patients in each GOLD group were on ICS/LABA + LAMA, although there is a possibility of stepping up or down treatment based on patient response. ICS might be preferred by physicians as an add-on for exacerbation prevention, especially for patients at high risk. In addition, given that patients with concurrent asthma only accounted for $8.8 \%$, the widespread use of ICS/LABA was unlikely to be due to this concomitant condition. Mucolytics were the third most frequently prescribed class of medications (15.8\%), which might help relieve symptoms and improve quality of life (25-27). Non-recommended medications were commonly prescribed, an issue also highlighted by Fang, et al. (TCM, 16.3\%; antibiotics, 60.5\%) (13) and by Ding, et al. (16.5\%) (14).

GOLD 2019 recommends the use of blood eosinophil count as a biomarker to guide follow-up treatment with ICS, with $\geq 300$ cells/ $\mu \mathrm{L}$ favouring ICS prescription while $<100$ cells $/ \mu \mathrm{L}$ opposing the use of ICS (28). Although prescriptions of ICS therapies did not seem to be based on blood eosinophil counts in our patient population, our longitudinal data on treatment response provides further evidence on the use of higher blood eosinophil counts to predict better response to ICS therapy. 
Regional inequality in infrastructure and qualified personnel remains an obstacle to delivering highquality health care to most Chinese residents (29). Specialised respiratory departments are instituted mainly in secondary and tertiary hospitals, but substantial disparities exist in the capability, expertise, and performance of respiratory care between hospitals of these two tiers and in different regions (30). Investments and efforts to improve health care should be tilted towards the rural regions and secondary hospitals, which may help address the disparities in COPD burden revealed in our study.

This study has several limitations. First, only patients who visited the outpatient respiratory department of secondary and tertiary hospitals who were diagnosed with COPD were enrolled. Given the previously reported serious issue of underdiagnosis (1) and aforementioned inconsistency in the proportions of GOLD stages characterised by our study and others $(1,2,18)$, it is likely that a fraction of COPD patients, especially those at early stages and with few or mild symptoms, were are not represented by the study. Also, patients at GOLD stage 0 , a controversial category usually defined as the presence of COPD symptoms without airflow obstruction (31), were excluded by the criterion of $\mathrm{FEV}_{1} / \mathrm{FVC}<70 \%$ in this study. Thus, caution should be taken when extrapolating the results from the outpatients in this study to the general patient population. Baseline data on maintenance medications were collected retrospectively and included both initial and follow-up treatments; therefore, non-adherence to GOLD guidelines cannot be precisely estimated. Baseline data on symptoms and exacerbations were recalled retrospectively by patients, possibly resulting in potential incompleteness. Finally, data were confined to results of examinations and tests performed in routine clinical practice, and therefore not all data were available for each patient (e.g. blood tests, fractional exhaled nitric oxide tests, or chest computed tomography scans).

To improve patient outcomes, these data indicate that focussed and widespread physician education on which classes of COPD treatment at which stages give the most effective outcomes would be beneficial, as would an increased implementation of patient education and vaccination against influenza and pneumonia for patients at risk of exacerbations with COPD.

\section{Conclusions}

Moderate-to-severe airflow obstruction, more symptoms, and high risk of exacerbations are prevalent among patients diagnosed with COPD in China. Maintenance therapies are not prescribed with full adherence to guideline recommendations.

\section{List Of Abbreviations}




\begin{tabular}{|ll|}
\hline Abbreviation & Phrase in full \\
\hline BOLD & Burden of Obstructive Lung Disease \\
\hline CAT & COPD Assessment Test \\
\hline COPD & chronic obstructive pulmonary disease \\
\hline EOS & blood eosinophil count \\
\hline FAS & full analysis set \\
\hline FEV1 & forced expiratory volume in one second \\
\hline FVC & forced vital capacity \\
\hline GOLD & Global Initiative for Chronic Obstructive Lung Disease \\
\hline ICF & informed consent form \\
\hline ICS & inhaled corticosteroid \\
\hline LABA & long-acting $\beta 2$ agonist \\
\hline LAMA & long-acting anti-muscarinic agent \\
\hline mMRC & modified Medical Research Council dyspnoea scale \\
\hline SABA & short-acting $\beta 2$ agonist \\
\hline SAMA & short-acting anti-muscarinic agent \\
\hline SAS & statistical analysis system \\
\hline SD & standard deviation \\
\hline TCM & traditional Chinese medicine \\
\hline USD & United States dollar \\
\hline
\end{tabular}

\section{Declarations}

\section{Ethics approval and consent to participate}

Written informed consent was obtained from all participants. The Ethics Committee of the China-Japan Friendship Hospital, the leading site, approved the study protocol and informed consent form (ICF) prior to study initiation (approval number 2016-97). All patients participating in this study voluntarily signed the ICF and received a copy before study initiation. The study was approved by ethics committees at individual study centres and performed in full conformance with the Declaration of Helsinki and Good Clinical Practice. 


\section{Consent for publication}

Not applicable.

\section{Availability of data and materials}

The datasets used and/or analysed during the current study are available from the corresponding author on reasonable request.

\section{Competing interests}

TY, BCai, BCao, JK, FW, YC, WJ, and CW declare that they have no competing interests. HS is an employee of AstraZeneca China.

\section{Funding}

This work was supported by AstraZeneca China. The funder collaborated with researchers in the design and planned statistical analyses.

\section{Author contributions}

TY, BCai, BCao, JK, FW, YC, WJ, HS, and CW provided input into the concept and design of the study, helped draft each stage of the manuscript, and read and approved the final version for submission. All authors had full access to all the data in the study and agreed to be accountable for the content of the manuscript.

\section{Acknowledgements}

The authors would like to thank Dr Xinlei Yu of Nucleus Global for providing medical writing support, funded by AstraZeneca China.

\section{References}

1. Fang L, Gao P, Bao H, Tang X, Wang B, Feng Y, et al. Chronic obstructive pulmonary disease in China: a nationwide prevalence study. Lancet Respir Med. 2018;6:421-30.

2. Wang $C, X u$ J, Yang L, Xu Y, Zhang X, Bai C, et al. Prevalence and risk factors of chronic obstructive pulmonary disease in China (the China Pulmonary Health [CPH] study): a national cross-sectional study. Lancet. 2018;391:1706-17. 
3. Zhong N, Wang C, Yao W, Chen P, Kang J, Huang S, et al. Prevalence of chronic obstructive pulmonary disease in China: a large, population-based survey. Am J Respir Crit Care Med. 2007; 176:753-60.

4. Collaborators GBDCRD. Global, regional, and national deaths, prevalence, disability-adjusted life years, and years lived with disability for chronic obstructive pulmonary disease and asthma, 19902015: a systematic analysis for the Global Burden of Disease Study 2015. Lancet Respir Med. 2017;5:691-706.

5. Yin P, Wang H, Vos T, Li Y, Liu S, Liu Y, et al. A subnational analysis of mortality and prevalence of COPD in China from 1990 to 2013: findings from the global burden of disease study 2013. Chest. 2016;150:1269-80.

6. WHO COPD fact sheet. https://www.who.int/news-room/fact-sheets/detail/chronic-obstructivepulmonary-disease-(copd). Accessed 01 Jan 2018.

7. World Bank data on the total population of China. https://data.worldbank.org/indicator/SP.POP.TOTL?locations=CN. Accessed 09 July 2020.

8. Khakban A, Sin DD, FitzGerald JM, McManus BM, Ng R, Hollander Z, et al. The projected epidemic of chronic obstructive pulmonary disease hospitalizations over the next 15 years. A population-based perspective. Am J Respir Crit Care Med. 2017;195:287-91.

9. GOLD. Global Strategy For The Diagnosis, Management, And Prevention Of Chronic Obstructive Pulmonary Disease Updated 2016. 2016. https://goldcopd.org/gold-reports/. Accessed 01 Jan 2018.

10. Chinese Society of Respiratory Disease. The guideline for the diagnosis and treatment of chronic obstructive pulmonary disease (2013 revision). Zhonghua Jie He He Hu Xi Za Zhi. 2013;36:255-64.

11. Cui Y, Dai Z, Luo L, Chen P, Chen Y. Classification and treatment of chronic obstructive pulmonary disease outpatients in China according to the Global Initiative for Chronic Obstructive Lung Disease (GOLD) 2017: comparison with GOLD 2014. J Thorac Dis. 2019;11:1303-15.

12. Kurmi OP, Davis KJ, Hubert Lam KB, Guo Y, Vaucher J, Bennett D, et al. Patterns and management of chronic obstructive pulmonary disease in urban and rural China: a community-based survey of 25 000 adults across 10 regions. BMJ Open Respir Res. 2018;5:e000267.

13. Fang X, Li S, Gao L, Zhao N, Wang X, Bai C. A short-term educational program improved physicians' adherence to guidelines for COPD and asthma in Shanghai. Clin Transl Med. 2012;1:13.

14. Ding B, Small M, Bergstrom G, Holmgren U. COPD symptom burden: impact on health care resource utilization, and work and activity impairment. Int J Chron Obstruct Pulmon Dis. 2017;12:677-89.

15. Ting Yang BC, Bin Cao, Jian Kang, Fuqiang Wen, Wanzhen Yao, Jinping Zheng, Xia Ling, Hongyan Shang, Chen Wang. REALizing and improving management of stable COPD in China: a multi-center, prospective, observational study to realize the current situation of COPD patients in China (REAL) rationale, study design, and protocol. BMC Pulm Med. 2020; doi: 10.1186/s12890-019-1000-x.

16. GOLD. Global Strategy For The Diagnosis, Management, And Prevention Of Chronic Obstructive Pulmonary Disease 2017 Report. 2017. https://goldcopd.org/wp-content/uploads/2017/02/wmsGOLD-2017-FINAL.pdf. Accessed 01 Jan 2018. 
17. Yang Y, Mao J, Ye Z, Li J, Zhao H, Liu Y. Risk factors of chronic obstructive pulmonary disease among adults in Chinese mainland: A systematic review and meta-analysis. Respir Med. 2017;131:158-65.

18. Buist AS, McBurnie MA, Vollmer WM, Gillespie S, Burney P, Mannino DM, et al. International variation in the prevalence of COPD (the BOLD Study): a population-based prevalence study. Lancet. 2007;370:741-50.

19. Sun $L$, Chen Y, Wu R, Lu M, Yao W. Changes in definition lead to changes in the clinical characteristics across COPD categories according to GOLD 2017: a national cross-sectional survey in China. Int J Chron Obstruct Pulmon Dis. 2017;12:3095-102.

20. Agusti A, Edwards LD, Celli B, Macnee W, Calverley PM, Mullerova H, et al. Characteristics, stability and outcomes of the 2011 GOLD COPD groups in the ECLIPSE cohort. Eur Respir J. 2013;42:636-46.

21. Lange $P$, Marott JL, Vestbo J, Olsen KR, Ingebrigtsen TS, Dahl M, et al. Prediction of the clinical course of chronic obstructive pulmonary disease, using the new GOLD classification: a study of the general population. Am J Respir Crit Care Med. 2012;186:975-81.

22. Goossens LM, Leimer I, Metzdorf N, Becker K, Rutten-van Molken MP. Does the 2013 GOLD classification improve the ability to predict lung function decline, exacerbations and mortality: a posthoc analysis of the 4-year UPLIFT trial. BMC Pulm Med. 2014;14:163.

23. Soriano JB, Lamprecht B, Ramirez AS, Martinez-Camblor P, Kaiser B, Alfageme I, et al. Mortality prediction in chronic obstructive pulmonary disease comparing the GOLD 2007 and 2011 staging systems: a pooled analysis of individual patient data. Lancet Respir Med. 2015;3:443-50.

24. Kobayashi S, Hanagama M, Ishida M, Sato H, Ono M, Yamanda S, et al. Clinical characteristics and outcomes in Japanese patients with COPD according to the 2017 GOLD classification: the Ishinomaki COPD Network Registry. Int J Chron Obstruct Pulmon Dis. 2018;13:3947-55.

25. Tse HN, Raiteri L, Wong KY, Yee KS, Ng LY, Wai KY, et al. High-dose N-acetylcysteine in stable COPD: the 1-year, double-blind, randomized, placebo-controlled HIACE study. Chest. 2013;144:106-18.

26. Zheng J-P, Wen F-Q, Bai C-X, Wan H-Y, Kang J, Chen P, et al. Twice daily N-acetylcysteine $600 \mathrm{mg}$ for exacerbations of chronic obstructive pulmonary disease (PANTHEON): a randomised, double-blind placebo-controlled trial. Lancet Respir Med. 2014;2:187-94.

27. Dal Negro RW, Wedzicha JA, Iversen M, Fontana G, Page C, Cicero AF, et al. Effect of erdosteine on the rate and duration of COPD exacerbations: the RESTORE study. Eur Respir J 2017;50:1700711.

28. Singh D, Agusti A, Anzueto A, Barnes PJ, Bourbeau J, Celli BR, et al. Global Strategy for the Diagnosis, Management, and Prevention of Chronic Obstructive Lung Disease: the GOLD science committee report 2019. Eur Respir J. 2019;53:1900164.

29. National Bureau of Statistics of China. China Statistical Yearbook 2018. http://www.stats.gov.cn/tjsj/ndsj/2018/indexeh.htm. Accessed 16 March 2020.

30. Pengjun Zhang BP, Yang Xu, Huifang Zhang, Xiangyu Luo, Fen Dong, Ting Yang, Huaping Dai, Chen Wang. Survey of current respiratory departments setup in China. Chin J Hosp Admin. 2017;33:82933. 
31. Stavem K, Sandvik L, Erikssen J. Can global initiative for Chronic Obstructive Lung Disease stage 0 provide prognostic information on long-term mortality in men? Chest. 2006;130:318-25.

\section{Figures}
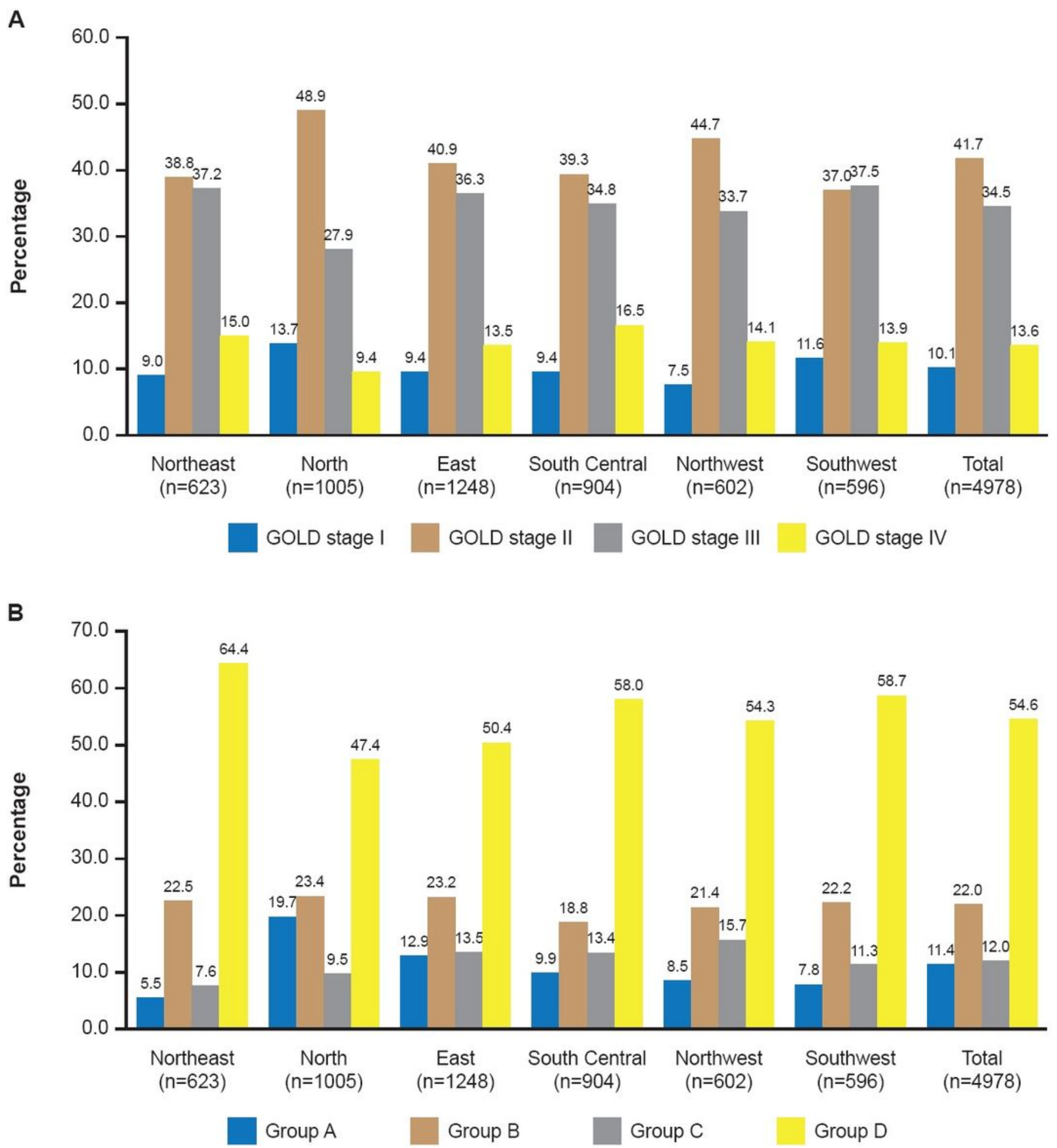

Figure 1 
Severity distribution of COPD across six geographical regions in China. (A) Distribution of airway limitation stages. (B) Distribution of Group A-D assessed as per GOLD 2016. Percentages of patients in each group are indicated. COPD, chronic obstructive pulmonary disease; GOLD, Global Initiative for Chronic Obstructive Lung Disease.
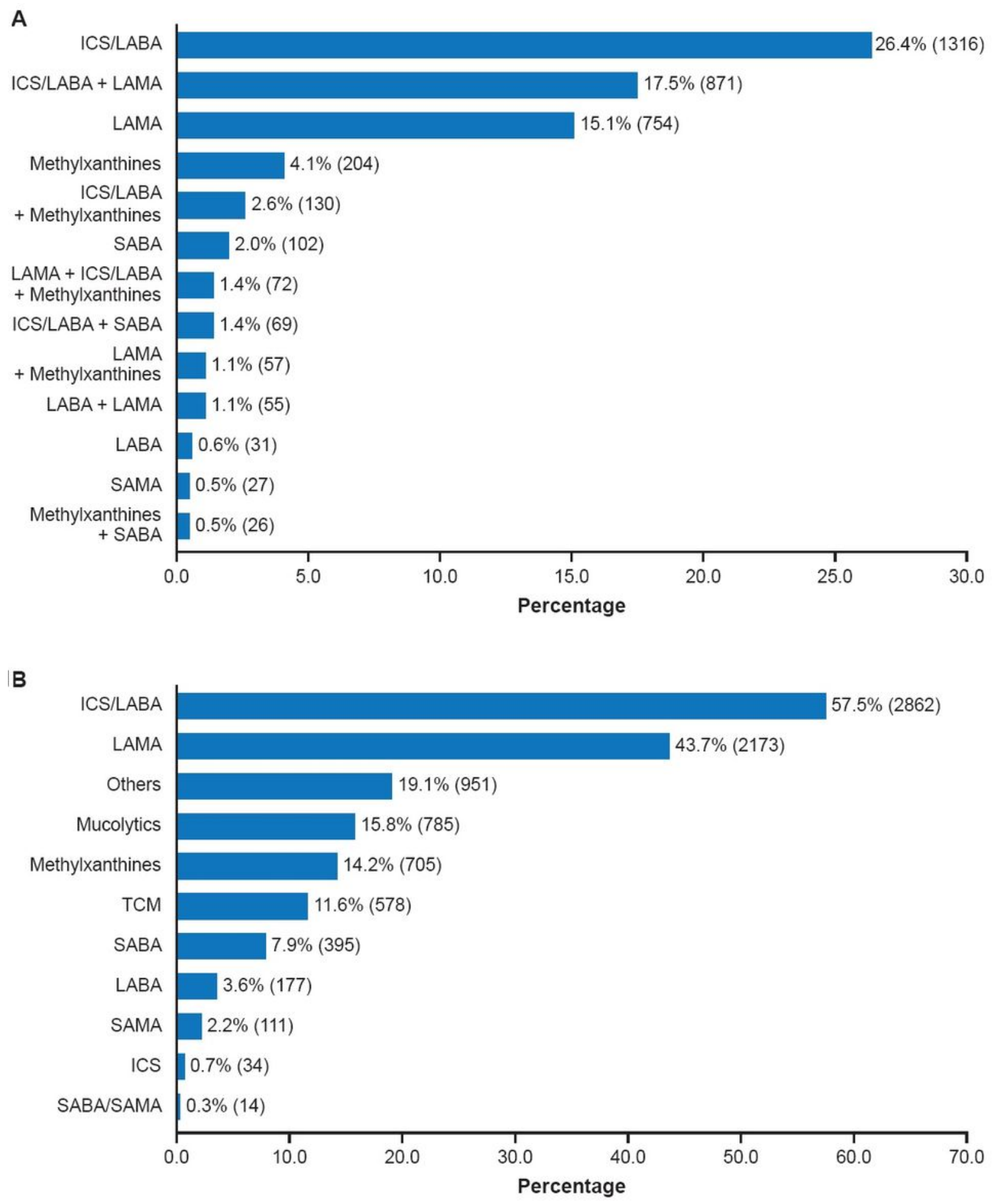

Figure 2 
Distribution of maintenance medications for COPD. (A) Distribution of prescribed mono- and combination maintenance therapies for COPD. Mono- or combination therapies with bronchodilators and/or ICS (prescribed for $\geq 0.5 \%$ of patients) are shown, with no prohibition of use with mucolytics and other class of medications. (B) Distribution of medications prescribed in any form for COPD. Percentages and numbers of patients prescribed with each class of medications are indicated. COPD, chronic obstructive pulmonary disease; ICS, inhaled corticosteroid; LABA, long-acting beta2-agonist; LAMA, long-acting muscarinic antagonist; SABA, short-acting beta2-agonist; SAMA, short-acting muscarinic antagonist; TCM, traditional Chinese medicine.

\section{Supplementary Files}

This is a list of supplementary files associated with this preprint. Click to download.

- REALIFigureE1.pdf

- REALIFigureE2.pdf

- REALISupplementarytables.docx 